\title{
Synthesis of Model BC Bicycles of Taxol Using C10-C11 Ring-Closing Metathesis Strategy
}

Stéphanie Schiltz, ${ }^{\mathrm{a}}$ Cong Ma, ${ }^{\mathrm{a}}$ Louis Ricard, ${ }^{\mathrm{b}}$ Joëlle Prunet ${ }^{\mathrm{a}, *}$

${ }^{a}$ Laboratoire de Synthèse Organique, UMR CNRS 7652, Ecole Polytechnique, DCSO, F-91128 Palaiseau, France.Email: joelle.prunet@polytechnique.fr

${ }^{b}$ Laboratoire Hétéroéléments et Coordination, UMR CNRS 7653, Ecole Polytechnique, DCPH, F-91128 Palaiseau, France

\begin{abstract}
Model BC ring-systems of taxol 23b and 28b, which lack an oxygenated substituent at C7, have been efficiently synthesized. The key step is a ring-closing metathesis (RCM) to form the 8-membered B ring between $\mathrm{C} 10$ and $\mathrm{C} 11$. Comparison of the metathesis reaction in this route with the RCM used in a previous study with similar substrates is highlighted.
\end{abstract}

Keywords: Taxol, metathesis, cyclization, ruthenium

Taxol $^{\circledR} \mathbf{1}$ and Taxotere ${ }^{\circledR} \mathbf{2}$ are very effective therapeutic agents for the treatment of breast and ovarian cancer. ${ }^{1}$ Six research groups have completed the total synthesis of taxol, and numerous synthetic works have been published since its isolation. ${ }^{2}$ In the course of our studies towards the synthesis of this molecule, we planned a semi-convergent retrosynthesis of compound 3, which is an intermediate in Holton's synthesis (Scheme 1). ${ }^{2 \mathrm{~b}}$ The A ring would be installed at a late stage by an intramolecular aldol reaction on a diketone at $\mathrm{C} 13$ and $\mathrm{C} 11$ (Compound 4). ${ }^{3}$ Bicycle 5 would be formed by a ring-closing metathesis (RCM) that would close the B ring between $\mathrm{C} 10$ and $\mathrm{C} 11$. The metathesis precursor $\mathbf{6}$ would be prepared by addition of the lithium derivative of vinyl bromide 8 to aldehyde 7. We wish to report here the synthesis of models of bicycle 5, which lack the alkoxy group at $\mathrm{C} 7$ and the ketal function at $\mathrm{C} 13 .{ }^{4}$

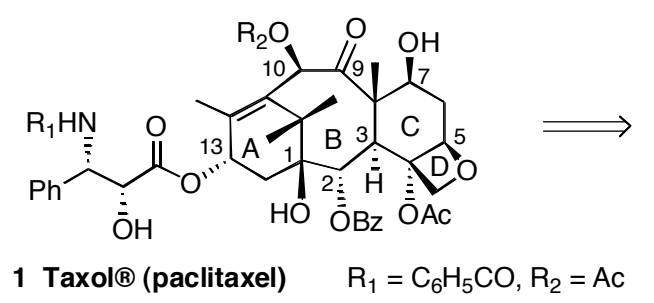

2 Taxotere $\circledast$ (docetaxel) $\mathrm{R}_{1}=t-\mathrm{BuOCO}, \mathrm{R}_{2}=\mathrm{H}$
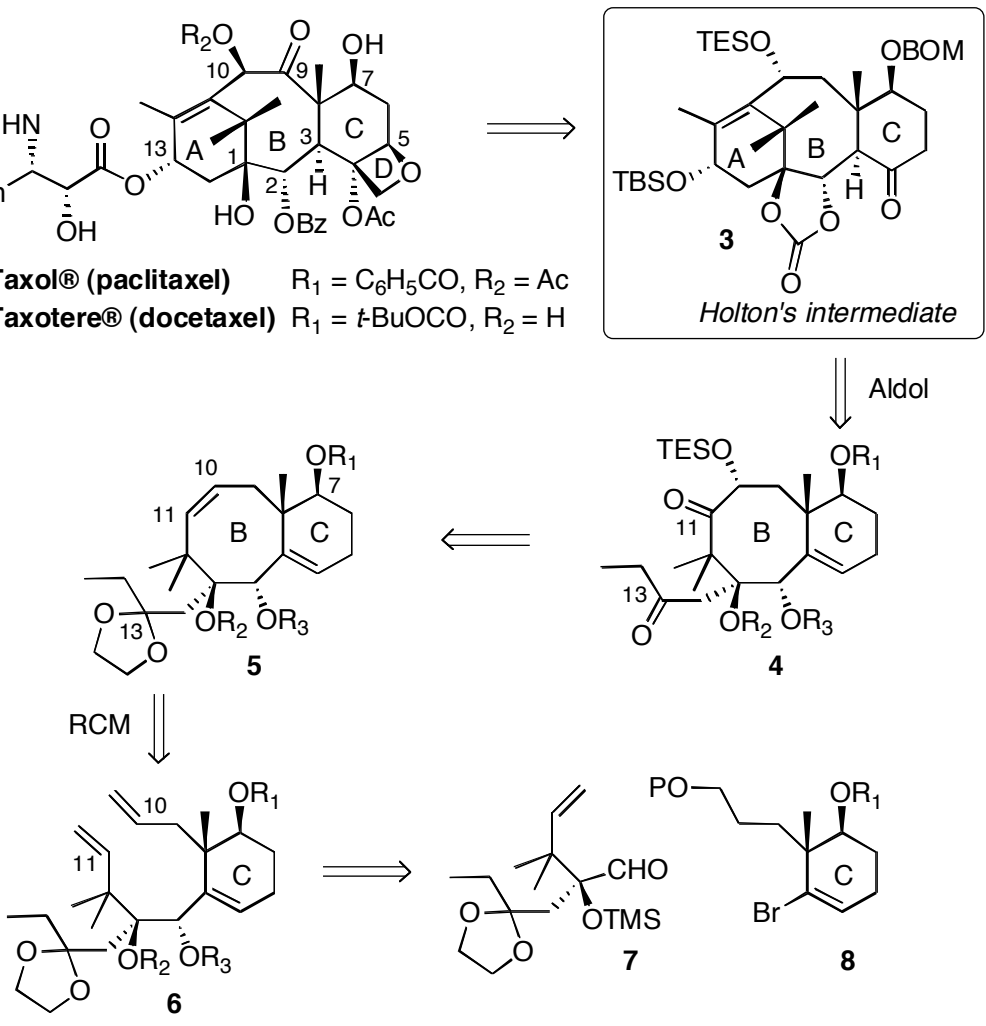

\section{Scheme 1}


Model aldehyde 9 was prepared as a racemic mixture. Barbier reaction between isoprenyl bromide and valeraldehyde according to Luche's conditions, ${ }^{5}$ followed by oxidation with iodoxybenzoic acid, ${ }^{6}$ afforded ketone $\mathbf{1 0}$ in excellent overall yield. Homologation of this ketone to aldehyde $\mathbf{9}$ was effected by conversion to the corresponding cyanohydrin $11\left(\mathrm{TMSCN}_{\mathrm{ZnI}}\right)_{2}$ and reduction by DIBAL-H. ${ }^{7}$

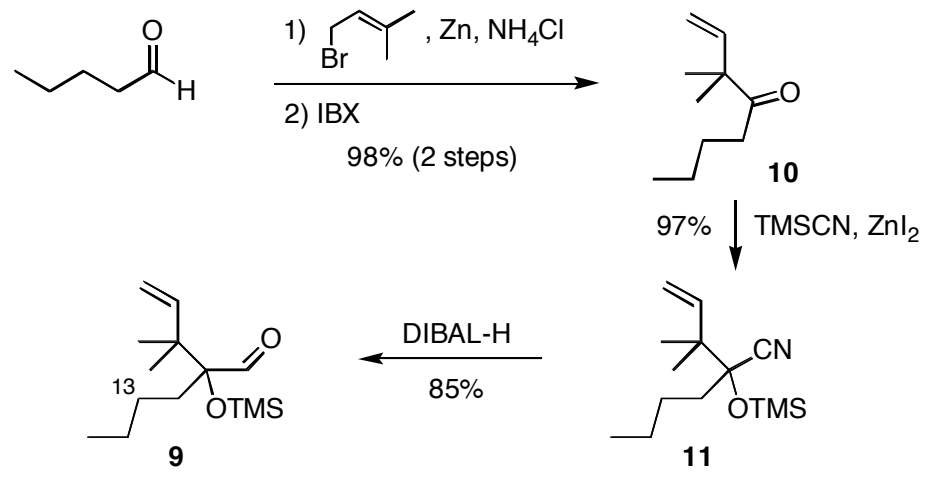

\section{Scheme 2}

Vinyl bromide 12 was synthesized as an enantiopure compound. The primary alcohol of known optically active diol $\mathbf{1 3}^{8}$ was protected as its trityl ether. ${ }^{9}$ Other protecting groups such as triisopropylsilyl (TIPS) or $p$-methoxybenzyl (PMB) ethers were also installed, but the yield of coupling between 9 and 12 revealed very dependent on this protecting group. We had originally planned to convert ketone $\mathbf{1 4}$ into vinyl bromide 12 by treatment of the corresponding hydrazone with NBS, ${ }^{10}$ but formation of the hydrazone is plagued by an important quantity of azine. ${ }^{11}$ Ketone $\mathbf{1 4}$ was thus transformed into vinyl triflate $\mathbf{1 5}$ in excellent yield, and this compound afforded vinyl bromide 12 via the corresponding trimethylvinyl stannane derivative. $^{12}$
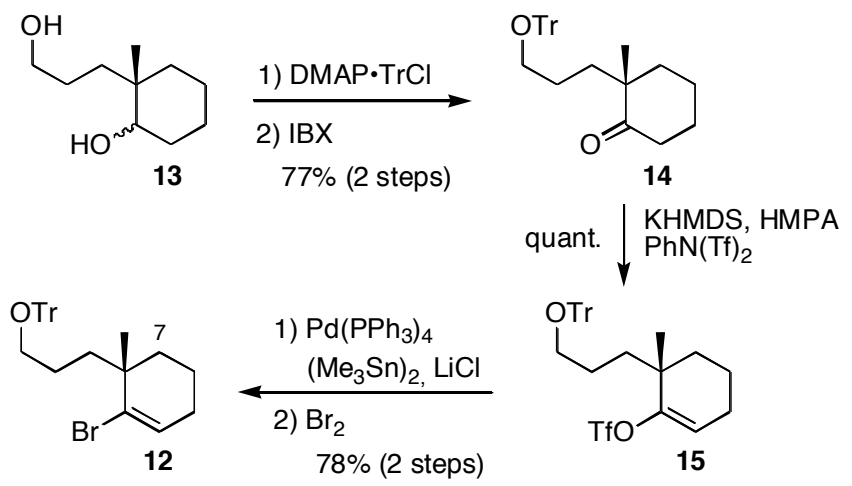

\section{Scheme 3}

The coupling reaction of compounds $\mathbf{9}$ and $\mathbf{1 2}$ was then undertaken. Halogen-metal exchange was best performed by addition of a THF solution of bromide 12 into a solution of $t$-BuLi in THF. Subsequent addition of aldehyde 9 furnished the desired coupling product as a mixture of 2 diastereomers. Deprotection of the trimethylsilyl ether then gave diols 16a and 16b, which were easily separated by column chromatography (Scheme 4). The coupling reaction is very stereoselective, favoring the trans diols ${ }^{13}$ (two isomers are obtained since the starting aldehyde is racemic). This diastereoselectivity had already been observed for similar coupling reactions performed in our laboratory during previous studies on taxol precursors. ${ }^{14}$ The stuctures of both coupling products were secured by X-ray crystallographic analysis of diol $\mathbf{1 6} \mathbf{b}$ for the desired diastereomer (Scheme 4), and of the derived triol 20a for the other one. ${ }^{15}$ 

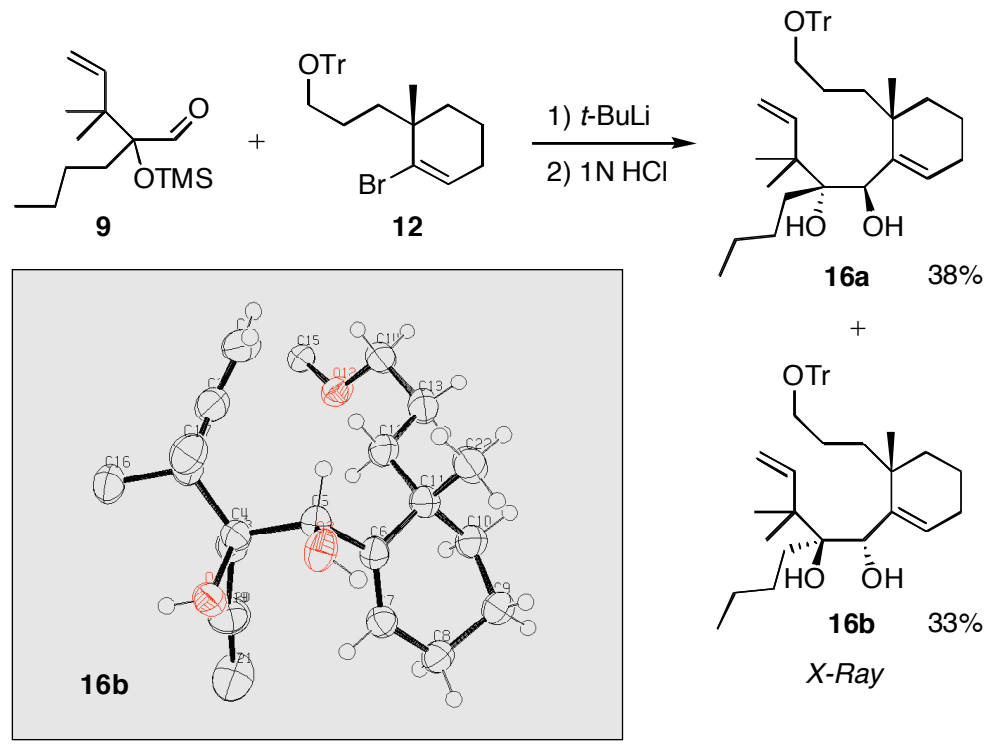

\section{Scheme 4}

We decided to convert both isomers to substrates for the metathesis reaction, in order to compare the influence of the diol stereochemistry on the RCM. The primary trityl group had to be converted into a terminal olefin. Diols 16a and $\mathbf{1 6} \mathbf{b}$ were first protected as their carbonate derivatives 17a and 17b, respectively (Scheme 5). Treatment with sodium hydride and carbonyldiimidazole ${ }^{4 \mathrm{~b}}$ only gave the desired products in $10 \%$ yield, along with some decomposed material. Fortunately, 17a and 17b could be obtained by heating in toluene at reflux in the presence of carbonyldiimidazole only. The trityl group in 17a and $\mathbf{1 7} \mathbf{b}$ was first deprotected with formic acid, and the corresponding formate esters were dissolved in dioxane and hydrolyzed with $1 \mathrm{~N}$ aqueous sodium hydroxide, leading to alcohols $\mathbf{1 8 a}$ and $\mathbf{1 8 b}$ in $78 \%$ and $93 \%$ yield, respectively. These compounds were obtained in a more direct fashion by treatment with Amberlyst-15 resin in methanol. The primary alcohols present in $\mathbf{1 8 a}$ and $\mathbf{1 8 b}$ were eliminated using Grieco's method, ${ }^{16}$ leading to the metathesis precursors $19 \mathrm{a}$ and $\mathbf{1 9 b}$.
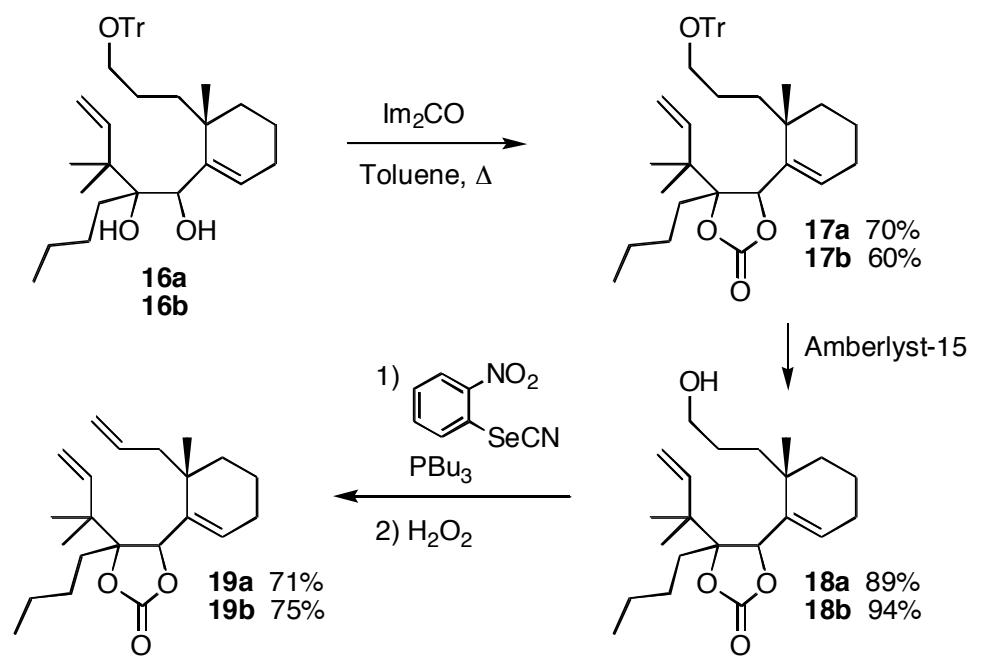

\section{Scheme 5}

Metathesis precursors 22a and 22b where the diol moiety is protected as an acetonide were also synthesized (Scheme 6). Diols 16a and 16b were transformed into the corresponding triols 20a and 20b 
with Amberlyst-15 resin in methanol, and treatment of these compounds with 2,2-dimethoxypropane and CSA furnished acetonides 21a and 21b in good overall yields (83\% and 80\%, respectively). Grieco's method was then used as before, leading to the desired products $\mathbf{2 2} \mathbf{a}$ and $\mathbf{2 2 \mathbf { b }}$.
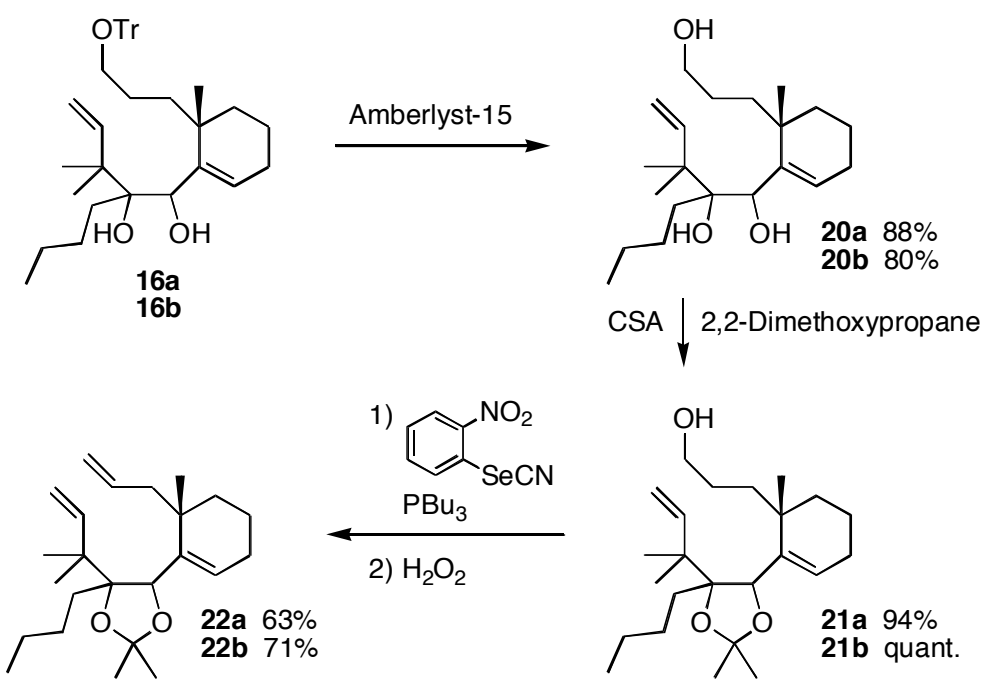

\section{Scheme 6}

The ring-closing metathesis (RCM) experiments were first tested with carbonate 19a, which possesses the wrong stereochemistry for taxol at $\mathrm{C} 1$ and $\mathrm{C} 2$. No cyclized product was observed with Grubbs $\mathbf{1}^{17}$ or Grubbs $2^{18}$ catalyst in 1,2-dichloroethane at reflux, and prolonged reaction times (several days) with the latter complex only led to decomposition products. However, when diastereomer $\mathbf{1 9 b}$ was submitted to 30 mol\% of Grubbs 1, after several days at ambient temperature, ${ }^{19}$ the corresponding cyclooctene $\mathbf{2 3 b}$ was produced in $65 \%$ yield as the $Z$ isomer exclusively (Scheme 7). Use of second-generation catalysts Grubbs 2 or [RuIMes] ${ }^{20}$ furnished the same product in comparable yields (69\% and $72 \%$, respectively), but the reaction was much faster (1 hour only).
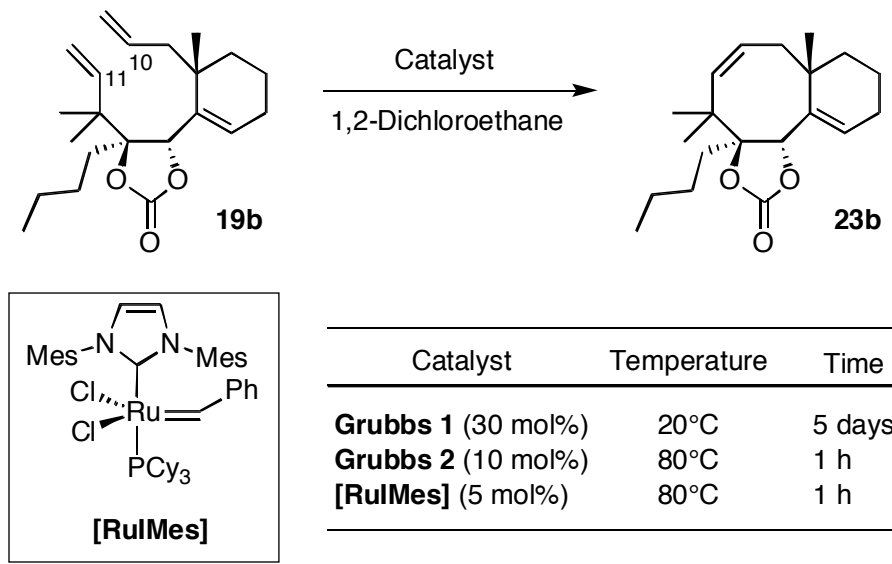

\begin{tabular}{cclc}
\hline \multicolumn{1}{c}{ Catalyst } & Temperature & Time & Yield \\
\hline Grubbs 1 (30 mol\%) & $20^{\circ} \mathrm{C}$ & 5 days & $65 \%$ \\
Grubbs 2 (10 mol\%) & $80^{\circ} \mathrm{C}$ & $1 \mathrm{~h}$ & $69 \%$ \\
[RulMes] (5 mol\%) & $80^{\circ} \mathrm{C}$ & $1 \mathrm{~h}$ & $72 \%$ \\
\hline
\end{tabular}

\section{Scheme 7}

These results are in sharp contrast with those obtained during our previous route to $\mathrm{BC}$ ring-systems of taxol, where the RCM took place between the C9 and the C10 carbons instead of C10-C11 on otherwise similar substrates. ${ }^{4}$ In those cases, the diastereomer presenting the wrong stereochemistry at the diol stereocenters (24a) did not cyclize with Grubbs 1, but produced the expected cyclooctene 25a with [RuIMes] (Scheme 8). ${ }^{21}$ The other diastereomer (24b) led to the kinetic trans cyclooctene $\boldsymbol{E}-\mathbf{2 5 b}$ with 
Grubbs 1, and to the cis 8-membered ring Z-25b with [RuIMes]. It seems that metathesis is much more difficult for the wrong diastereomer when the ring-closing reaction occurs at $\mathrm{C} 10-\mathrm{C} 11$ (this paper) rather than at C9-C10 (previous study), and much easier for the desired diastereomer. Of course, one cannot directly compare the two reactions, because the first carbene is formed on opposite sides of the molecules in each case. In the first route, it is formed on $\mathrm{C10}$, which is attached to the left-hand side of the molecule, and the reaction proceeds to close onto C9. In this work, the first carbene is formed on C10, but this carbon is attached to the right-hand side of the precursor, and ring-closure occurs at $\mathrm{C} 11$.
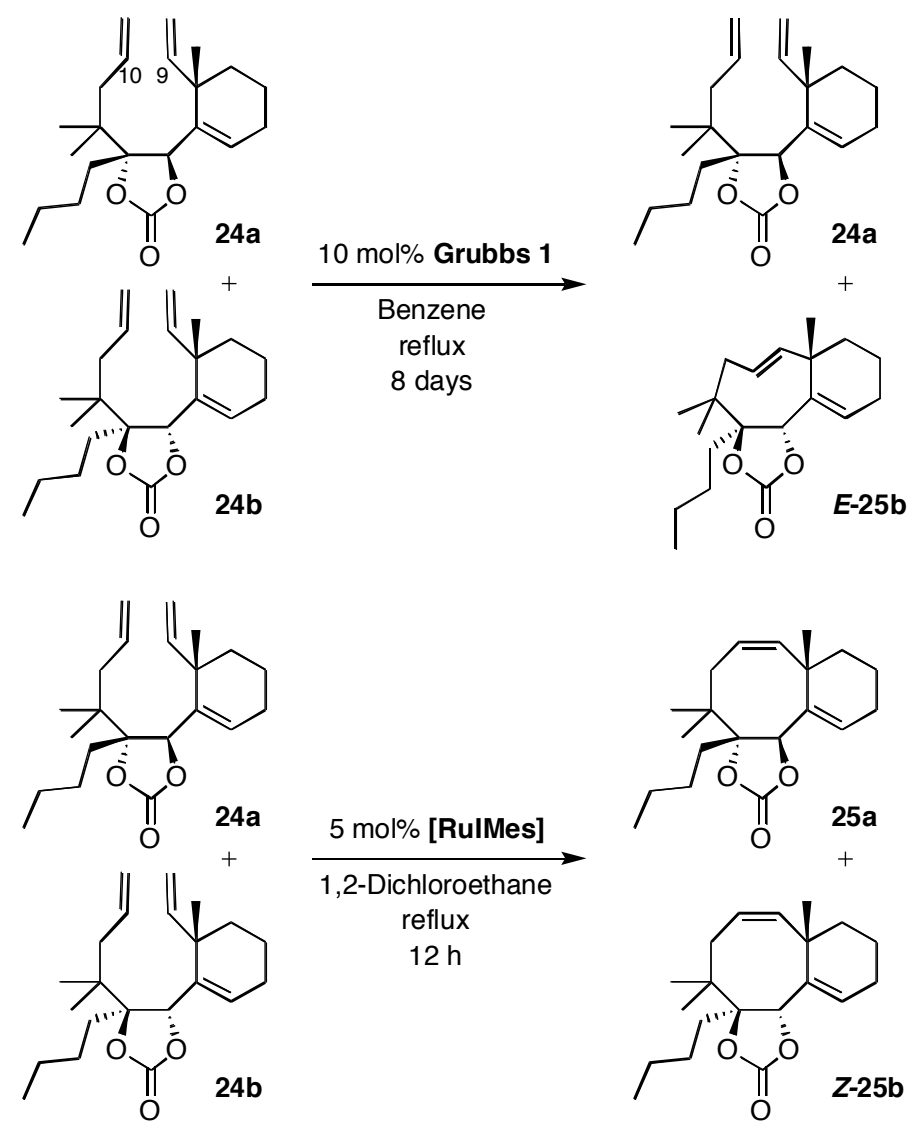

Scheme 8

Finally, the acetonide derivatives were subjected to Grubbs 2 catalyst. After 30 min in $\mathrm{CH}_{2} \mathrm{Cl}_{2}$ at reflux, diastereomer 22a only led to dimeric products $\mathbf{2 6}$ and 27 in a 3:1 ratio, favoring the symmetrical product (Scheme 9). Each dimer was produced as a 3:1 mixture of diasteromers. Cyclization of the other diastereomer $\mathbf{2 2 b}$ was exceptionally fast, and bicycle $\mathbf{2 8 b}$ was obtained in quantitative yield after only $5 \mathrm{~min}$ in 1,2-dichloroethane at reflux. 

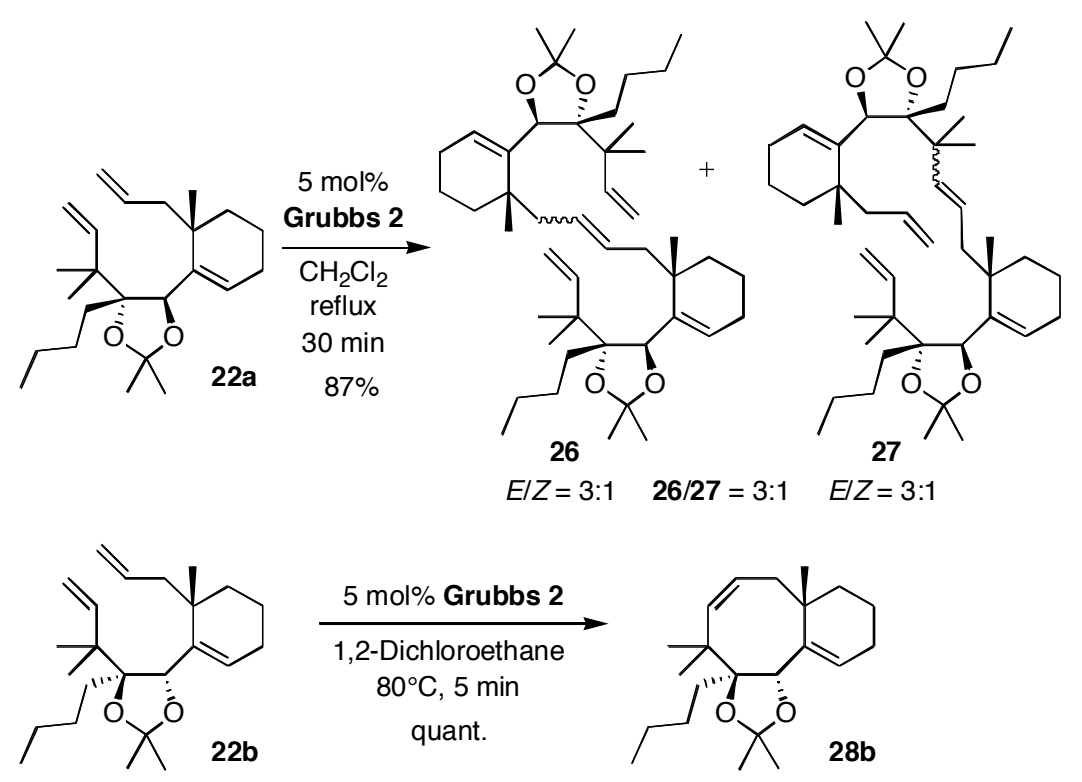

Scheme 9

Here also, the same comparison can be made with the RCM reactions of acetonides $29 \mathbf{a}$ and $\mathbf{2 9 b}$ from the previous study, which both cyclized with [RuIMes] after $12 \mathrm{~h}$ in 1,2-dichloroethane at reflux (Scheme 10). In the second route, cyclization with the wrong diastereomer is not possible, and much faster for the isomer which leads to model BC ring-systems of taxol.
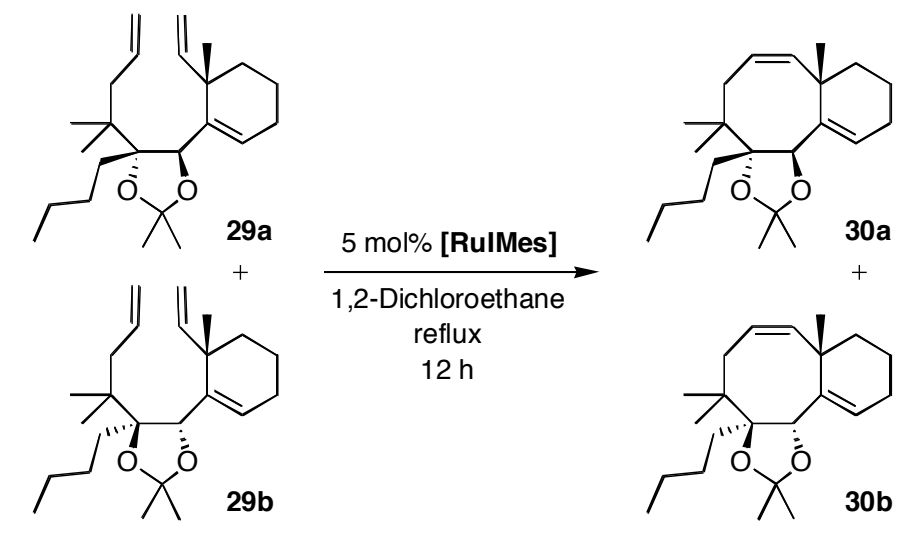

Scheme 10

In conclusion, we have synthesized highly functionalized cyclooctenes that are model precursors of taxol, using a ring-closing metathesis at $\mathrm{C} 10-\mathrm{C} 11$ to form the $\mathrm{B}$ ring. Direct comparison of this route with a previous study involving RCM at C9-C10 shows that the metathesis step works much more efficiently for the diastereomers useful for the synthesis using the C10-C11 strategy. We are currently preparing metathesis precursors with all the required functionalities for taxol.

Acknowledgments: Financial support was provided by the CNRS and the Ecole Polytechnique. S. S. acknowledges the Délégation Générale pour l'Armement (DGA) for a fellowship. We thank Dr. Ange Pancrazi for helpful discussions. 


\section{References}

(1) Oberlies, N. H.; Kroll, D. J. J. Nat. Prod. 2004, 67, 129.

(2) For reviews on the chemistry of taxol, see: Nicolaou, K. C.; Dai, W.-M.; Guy, R. K. Angew. Chem., Int. Ed. Engl. 1994, 33, 15; Kingston, D. G. I. Chem. Commun. 2001, 867.

For the total syntheses, see: (a) Nicolaou, K. C.; Yang, Z.; Liu, J. J.; Ueno, H.; Nantermet, P. G.; Guy, R. K.; Claiborne, C. F.; Renaud, J.; Couladouros, E. A.; Paulvannan, K.; Sorensen, E. J. Nature 1994, 367, 630. Nicolaou, K. C.; Nantermet, P. G.; Ueno, H.; Guy, R. K.; Couladouros, E. A.; Sorensen, E. J. J. Am. Chem. Soc. 1995, 117, 624. Nicolaou, K. C.; Liu, J. J.; Yang, Z.; Ueno, H.; Sorensen, E. J.; Claiborne, C. F.; Guy, R. K.; Hwang, C. K.; Nakada, M.; Nantermet, P. G. ibid. 1995, 117, 634. Nicolaou, K. C.; Yang, Z.; Liu, J. J.; Nantermet, P. G.; Claiborne, C. F.; Renaud, J.; Guy, R. K.; Shibayama, K. ibid. 1995, 117, 645. Nicolaou, K. C.; Ueno, H.; Liu, J. J.; Nantermet, P. G.; Yang, Z.; Renaud, J.; Paulvannan, K.; Chadha, R. ibid. 1995, 117, 653. (b) Holton, R. A.; Somoza, C.; Kim, H. B.; Liang, F.; Biediger, R. J.; Boatman, P. D.; Shindo, M.; Smith, C. C.; Kim, S.; Nadizadeh, H.; Suzuki, Y.; Tao, C.; Vu, P.; Tang, S.; Zhang, P.; Murthi, K. K.; Gentile, L. N.; Liu, J. H. J. Am. Chem. Soc. 1994, 116, 1597. Holton, R. A.; Kim, H. B.; Somoza, C.; Liang, F.; Biediger, R. J.; Boatman, P. D.; Shindo, M.; Smith, C. C.; Kim, S.; Nadizadeh, H.; Suzuki, Y.; Tao, C.; Vu, P.; Tang, S.; Zhang, P.; Murthi, K. K.; Gentile, L. N.; Liu, J. H. ibid. 1994, 116, 1599. (c) Masters, J. J.; Link, J. T.; Snyder, L. B.; Young, W. B.; Danishefsky, S. Angew. Chem., Int. Ed. Engl. 1995, 34, 1723. (d) Wender, P. A.; Badham, N. F.; Conway, S. P.; Floreancig, P. E.; Glass, T. E.; Gränicher, C.; Houze, J. B.; Jänichen, J.; Lee, D.; Marquess, D. G.; McGrane, P. L.; Meng, W.; Mucciaro, T. P.; Mühlebach, M.; Natchus, M. G.; Paulsen, H.; Rawlins, D. B.; Satkofsky, J.; Shuker, A. J.; Sutton, J. C.; Taylor, R. E.; Tomooka, K. J. Am. Chem. Soc. 1997, 119, 2755. Wender, P. A.; Badham, N. F.; Conway, S. P.; Floreancig, P. E.; Glass, T. E.; Houze, J. B.; Krauss, N. E.; Lee, D.; Marquess, D. G.; McGrane, P. L.; Meng, W.; Natchus, M. G.; Shuker, A. J.; Sutton, J. C.; Taylor, R. E. J. Am. Chem. Soc. 1997, 119, 2757. (e) Mukaiyama, T.; Shiina, I.; Iwadare, H.; Saitoh, M.; Nishimura, T.; Ohkawa, N.; Sakoh, H.; Nishimura, H.; Tani, Y.-I.; Hasegawa, M.; Yamada, K.; Saito, K. Chem. Eur. J. 1999, 5, 121. (f) Morihara, K.; Hara, R.; Kawahara, S.; Nishimori, T.; Nakamura, N.; Kusama, H.; Kuwajima, I. J. Am. Chem. Soc. 1998, 120, 12980.

(3) Swindell, C. S.; Patel, B. P. J. Org. Chem. 1990, 55, 3.

(4) For previous work from this laboratory on syntheses of model BC ring-systems of taxol involving RCM between C9 and C10, see: (a) Bourgeois, D.; Pancrazi, A.; Ricard, L.; Prunet, J. Angew. Chem., Int. Ed. Engl. 2000, 39, 725. (b) Bourgeois, D.; Mahuteau, J.; Pancrazi, A.; Nolan, S. P.; Prunet, J. Synthesis 2000, 869.

(5) Pétrier, C.; Luche, J.-L. J. Org. Chem. 1985, 50, 12.

(6) Frigerio, M.; Santagostino, M.; Sputore, S. J. Org. Chem. 1999, 64, 4537.

(7) For a similar homologation, see ref 4b and: Muller, B.; Delaloge, F.; den Hartog, M.; Férézou, J.-P.; Pancrazi, A.; Prunet, J.; Lallemand, J.-Y.; Neuman, A.; Prangé, T. Tetrahedron Lett. 1996, 37, 3313.

(8) Boukouvalas, J.; Cheng, Y.-X.; Robichaud, J. J. Org. Chem. 1998, 63, 228.

(9) Hernandez, O.; Chaudhary, S. K.; Cox, R. H.; Porter, J. Tetrahedron Lett. 1981, 22, 1491. 
(10) Pross, A.; Sternbell, S. Aust. J. Chem. 1970, 23, 989.

(11) Pross, A.; Sternbell, S. Aust. J. Chem. 1971, 24, 1437.

(12) Paquette, L. A.; Liang, S.; Wang, H.-L. J. Org. Chem. 1996, 61, 3268.

(13) Diols $\mathbf{1 6 a}$ and $\mathbf{1 6 b}$ would be trans if the B ring were closed.

(14) Bourgeois, D.; Maiti, G.; Pancrazi, A.; Prunet, J. Synlett 2000, 323.

(15) Crystallographic data for the structural analysis has been deposited with the Cambridge Crystallographic Data Centre, CCDC N 613208 for compound 16b and $\mathrm{N}^{\circ} 613209$ for compound 20a.

(16) Grieco, P. A.; Gilman, S.; Nishizawa, M. J. Org. Chem. 1976, 41, 1485; de Armas, P.; Garcia-Tellado, F.; Marrero-Tellado, J. J. Eur. J. Org. Chem. 2001, 4423.

(17) Schwab, P.; France, M. B.; Ziller, J. W.; Grubbs, R. H. Angew. Chem., Int. Ed. Engl. 1995, 34, 2039; Schwab, P.; Grubbs, R. H.; Ziller, J. W. J. Am. Chem. Soc. 1996, 118, 100.

(18) Scholl, M.; Ding, S.; Lee, C. W.; Grubbs, R. H. Org. Lett. 1999, 1, 953.

(19) Reaction was started with $10 \mathrm{~mol} \%$ catalyst, and $5 \mathrm{~mol} \%$ additional catalyst was added every day.

(20) Huang, J.; Stevens, E. D.; Nolan, S. P.; Petersen, J. L. J. Am. Chem. Soc. 1999, 121, 2674; Scholl, M.; Trnka, T. M.; Morgan, J. P.; Grubbs, R. H. Tetrahedron Lett. 1999, 40, 2247.

(21) The RCM reactions depicted on Scheme 8 were performed on mixtures of $\mathbf{2 4 a}$ and $\mathbf{2 4 b}$, as these diastereomers are inseparable by chromatography on silica gel. 